\title{
Controle de Plantas Daninhas na Cultura do Milho-Pipoca com Herbicidas Aplicados em Pós-Emergência ${ }^{1}$
}

\author{
Weed Control in Popcorn Maize using Post Emergence Herbicide
}

\begin{abstract}
JAKELAITIS, A. ${ }^{2}$, SILVA, A.F. ${ }^{3}$, SILVA, A.A. ${ }^{4}$, FERREIRA, L.R. ${ }^{4}$ e VIVIAN, R. ${ }^{5}$
RESUMO - Objetivou-se avaliar a eficiência de controle de plantas daninhas, a tolerância e a produção de milho-pipoca UFVM2 aos herbicidas atrazine $\left(1.500 \mathrm{~g} \mathrm{ha}^{-1}\right)$, foramsulfuron + iodosulfuron methyl sodium + atrazine $\left(15+1+1.500\right.$ e $\left.30+2+1.500 \mathrm{~g} \mathrm{ha}^{-1}\right)$, foramsulfuron + iodosulfuron methyl sodium $\left(15+1,30+2,45+3\right.$ e $\left.60+4 \mathrm{~g} \mathrm{ha}^{-1}\right)$, nicosulfuron + atrazine $(8+1.500$ e $\left.16+1.500 \mathrm{~g} \mathrm{ha}^{-1}\right)$ e nicosulfuron $\left(16 \mathrm{~g} \mathrm{ha}^{-1}\right)$. A aplicação dos herbicidas foi realizada aos 25 dias após a emergência da cultura. As plantas daninhas predominantes na área foram Brachiaria plantaginea, Brachiaria decumbens e Ipomoea spp. Os herbicidas foramsulfuron + iodosulfuron methyl sodium, em todas as doses testadas, proporcionaram maiores índices de toxidez à cultura, aos 7, 14 e 28 dias após a aplicação dos tratamentos (DAA). Todas as combinações de herbicidas proporcionaram controle acima de $90 \%$ para B. plantaginea e B. decumbens, aos 28 DAA. O nicosulfuron aplicado isoladamente proporcionou controle de apenas $80 \%$ e o atrazine não controlou essas espécies daninhas. Para Ipomoea spp., nenhum tratamento herbicida proporcionou controle equivalente ao da testemunha capinada. A competição das plantas daninhas resultou em menores teores de clorofila total, N, P e K no tecido foliar das plantas de milho-pipoca e menor rendimento de grãos. Para o cultivar UFVM2, as sulfoniluréias isoladas ou associadas ao atrazine não afetaram o estado nutricional da cultura, o rendimento e a capacidade de expansão dos grãos de milho-pipoca.
\end{abstract}

Palavras-chave: competição, sulfoniluréias, atrazine.

ABSTRACT - The efficiency of different herbicide combinations for weed control and tolerance and yield of UFVM2 popcorn maize were evaluated. The herbicide treatments and respective doses were: atrazine $\left(1.500 \mathrm{~g} \mathrm{ha}^{-1}\right)$; foramsulfuron + iodosulfuron methyl sodium + atrazine $(15+1+1.500$ and $\left.30+2+1.500 \mathrm{~g} \mathrm{ha}^{-1}\right)$; foramsulfuron + iodosulfuron methyl sodium $(15+1,30+2,45+3$, and $\left.60+4 \mathrm{~g} \mathrm{ha}^{-1}\right)$; nicosulfuron + atrazine $\left(8+1.500\right.$ and $\left.16+1.500 \mathrm{~g} \mathrm{ha}^{-1}\right)$ and nicosulfuron $\left(16 \mathrm{~g} \mathrm{ha}^{-1}\right)$. The herbicides were applied 25 days after crop emergence. The predominant weeds in the area were Brachiaria plantaginea, Brachiaria decumbens, and Ipomoea spp. The herbicides foramsulfuron + iodosulfuron methyl sodium in all doses provided the highest rates of toxicity in popcorn maize 7, 14, and 28 days after application (DAA). All herbicide combinations controlled over $90 \%$ of $\boldsymbol{B}$. plantaginea and B. decumbens up to the 28 DAA. Nicosulfuron controlled only $80 \%$ with no atrazine control being observed. The competition with the weeds resulted in lower contents of total chlorophyll, $N, P$, and $K$ in the leaf tissue of the popcorn maize plants and smaller grain yield. For the UFVM2 cultivar, the sulfonylureias isolated or associated to atrazine had no effect on the nutritional state of the culture, yield and kernel expansion volume of the maize-popcorn.

Key words: competition, sulfonylureias, atrazine.

Recebido para publicação em 29.11.2004 e na forma revisada em 5.9.2005.

Pesquisa financiada com apoio do CNPq.

2 Pós-doutorando em Fitotecnia, Departamento de Fitotecnia da Universidade Federal de Viçosa - UFV, 36570-000 Viçosa-MG; ${ }^{3}$ Bolsista de Iniciação Científica do Departamento de Fitotecnia da UFV; ${ }^{4}$ Professores do Departamento de Fitotecnia da UFV; ${ }^{5}$ Mestrando em Fitotecnia, Departamento de Fitotecnia da UFV. 


\section{INTRODUÇÃO}

Pertencente à mesma espécie botânica do milho comum (Zea mays), o milho-pipoca é considerado tipo duro, de grãos pequenos e pericarpo mais espesso entre os tipos de milho, diferenciando-se deste pela capacidade de seus grãos estourarem quando aquecidos, transformando-se em pipoca (Ziegler \& Ashman, 1994). Devido à maior importância dada aos caracteres de qualidade em programas de melhoramento genético da cultura, em detrimento dos caracteres agronômicos, as plantas de milho-pipoca apresentam-se menores, com menor número de folhas e com limbo foliar estreito, além de suas plântulas serem menos vigorosas e de crescimento inicial lento, quando comparadas àquelas de híbridos de milho comum (Ziegler \& Ashman, 1994). Conseqüentemente, o milho-pipoca manifesta menor capacidade competitiva quando cultivado sob interferência de plantas daninhas, comparado aos híbridos de milho comum.

Dos fatores que influenciam a interferência das plantas daninhas, destaca-se o período em que estas plantas competem com as culturas pelos recursos do ambiente, tornando-se necessário intervir com medidas de controle para minimizar os efeitos negativos dessa interferência (Silva et al., 2002). Na cultura do milho-pipoca, as medidas adotadas se restringem, na maioria dos casos, ao uso de herbicidas associados a outros métodos de controle (Kawazaki, 2001). Ademais, o controle químico de plantas daninhas tem se destacado pela eficiência, pela rapidez e pelo baixo custo; entretanto, a eficácia dos herbicidas é variável entre si e dependente das condições ambientais, da época de aplicação e da espécie daninha a ser controlada (Merotto Jr. et al., 1997).

Dentre os herbicidas recomendados para o milho comum em aplicação em pós-emergência e que são aplicados no milho-pipoca, destacam-se o atrazine e o nicosulfuron (Kawazaki, 2001). O primeiro controla espécies daninhas dicotiledôneas e algumas gramíneas anuais, podendo ser aplicado em pré e pós-emergência das plantas daninhas; já o nicosulfuron é utilizado principalmente no controle de gramíneas e algumas dicotiledôneas, em aplicações em pós-emergência (Rodrigues \& Almeida, 1998).
Cultivares de milho podem apresentar sensibilidade diferencial ao nicosulfuron, dependendo do estádio de desenvolvimento da planta, do ambiente e da dose utilizada (Gubbiga et al., 1995). Em milho-doce, Sullivan \& Bouw (1997) verificaram que plantas tratadas com nicosulfuron na dose de $50 \mathrm{~g} \mathrm{ha}^{-1}$, aplicado nos estádios de cinco e sete folhas expandidas, apresentaram diversos sintomas de injúria, enquanto aquelas tratadas com $25 \mathrm{~g} \mathrm{ha}^{-1}$, nos mesmos estádios, foram pouco afetadas. Trindade (1995) não constatou efeito significativo entre doses de nicosulfuron e cultivares de milho-pipoca, mas observou danos na cultura à medida que se aumentavam as doses do herbicida. Para o cultivar de milhopipoca IAC 112, Kawazaki (2001) não observou redução no rendimento da cultura quando esta foi manejada com nicosulfuron na dose de $24 \mathrm{~g} \mathrm{ha}^{-1}$, em mistura com atrazine.

A pouca disponibilidade de informações técnicas específicas pode levar produtores de milho-pipoca a utilizarem práticas de manejo de plantas daninhas recomendadas para milho comum. Todavia, essas práticas nem sempre são apropriadas para a cultura, uma vez que a tolerância e a capacidade competitiva das plantas de milho-pipoca podem ser diferentes das de híbridos de milho comum. O objetivo deste trabalho foi avaliar a tolerância, o estado nutricional, o rendimento e a capacidade de expansão dos grãos do milho-pipoca UFVM2, em função da aplicação de diferentes combinações de herbicidas, assim como a eficiência desses herbicidas no controle de plantas daninhas.

\section{MATERIAL E MÉTODOS}

O experimento foi realizado em CoimbraMG, em Argissolo Vermelho Amarelo câmbico, com textura franco-argilo-arenosa. A análise química deste solo apresentou $\mathrm{pH}$ em água de 5,3; CTC, soma de bases, $\mathrm{H}+\mathrm{Al}$, Ca e $\mathrm{Mg}$ de 6,22, 2,26, 3,96, 1,6 e 0,5 $\mathrm{cmol}_{\mathrm{dm}} \mathrm{d}^{-3}$, respectivamente; $\mathrm{P}$ e $\mathrm{K}$ de 13,7 e $63 \mathrm{mg} \mathrm{dm}^{-3}$, respectivamente; e 2,76 dag $\mathrm{kg}^{-1}$ de matéria orgânica. Utilizou-se o sistema convencional de plantio, com uma aração e duas gradagens, realizadas sete dias antes da semeadura. O cultivar UFVM2 foi semeado em novembro de 2002, no espaçamento de 1,0 m entre linhas e com população aproximada de 
60.000 plantas ha ${ }^{-1}$. A adubação de plantio constou de $300 \mathrm{~kg} \mathrm{ha}^{-1}$ da formulação 8:28:16, e a de cobertura, de $70 \mathrm{~kg} \mathrm{ha}^{-1} \mathrm{de} \mathrm{N}$, aplicados na forma de uréia aos 30 dias após o plantio.

O delineamento experimental utilizado foi o de blocos ao acaso, com três repetições. As parcelas experimentais foram constituidas de cinco linhas da cultura com 5,0 m de comprimento, totalizando $25,0 \mathrm{~m}^{2}$, considerando como área útil as três linhas centrais de cada parcela. Os tratamentos consistiram da aplicação dos herbicidas: atrazine (1.500 $\mathrm{g} \mathrm{ha}^{-1}$ ), foramsulfuron + iodosulfuron methyl sodium + atrazine $\left(15+1+1.500\right.$ e $\left.30+2+1.500 \mathrm{~g} \mathrm{ha}^{-1}\right)$, foramsulfuron + iodosulfuron methyl sodium $\left(15+1 ; 30+2 ; 45+3 ;\right.$ e $\left.60+4 \mathrm{~g} \mathrm{ha}^{-1}\right)$, nicosulfuron $\left(16 \mathrm{~g} \mathrm{ha}^{-1}\right)$ e nicosulfuron + atrazine $(8+1.500$ e $16+1.500 \mathrm{~g} \mathrm{ha}^{-1}$ ), mais as testemunhas capinada e sem capina.

A população de plantas daninhas no momento da aplicação dos tratamentos era constituída principalmente por Brachiaria plantaginea (capim-marmelada), Brachiaria decumbens (capim-braquiária) e Ipomoea spp. (corda-de-viola). A pulverização dos herbicidas foi realizada aos 25 dias após a emergência do milho (DAE), com um pulverizador costal pressurizado com $\mathrm{CO}_{2}$, mantendo a pressão cons-

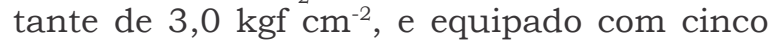
bicos XR 110.02, espaçados de 0,5 m e calibrados para aplicar $200 \mathrm{~L} \mathrm{ha}^{-1}$ de calda. No momento da aplicação, a velocidade do vento foi inferior a $5 \mathrm{~km} \mathrm{~h}^{-1}$, sendo a temperatura e a umidade relativa do ar de $25^{\circ} \mathrm{C}$ e $90 \%$, respectivamente. Os valores de precipitação pluvial observados durante a condução do ensaio foram também registrados.

Avaliações visuais de toxicidade dos herbicidas à cultura, da cobertura vegetal das parcelas e da porcentagem de controle de $B$. plantaginea e $B$. decumbens foram realizadas aos 7, 14 e 28 dias após aplicação dos tratamentos (DAA). No florescimento do milho determinaram-se o teor relativo de clorofila na folha (indice SPAD), medido com o clorofilômetro (modelo Minolta), e os teores de macronutrientres (N, P, K, Ca, Mg e S). As leituras efetuadas com o medidor de clorofila foram feitas na folha oposta e abaixo da espiga, em dois pontos situados na parte central da folha e a dois centímetros da margem, em dez plantas por parcela. As folhas em que foram realizadas as leituras foram coletadas, secas em estufa de ventilação forçada a $70{ }^{\circ} \mathrm{C}$ até massa constante e posteriormente moídas. Parte desse material foi submetida à digestão sulfúrica, sendo o teor de $\mathrm{N}$ orgânico dosado com reagente de Nessler (Jackson, 1958). Outra parte do material foi submetida à digestão nitro-perclórica, sendo posteriormente determinado o teor de $\mathrm{K}$, por fotometria de emissão de chama; os de Ca e Mg, por espectrofotometria de absorção atômica; o de S, por turbidimetria do sulfato; e o de $\mathrm{P}$, pelo método da vitamina C modificado (Braga \& Deffelipo, 1974).

O milho-pipoca foi colhido em março de 2003 e, em pré-colheita, determinaram-se o estande, a porcentagem de infestação de Ipomoea spp., o rendimento de grãos corrigido para $13 \%$ de umidade e a capacidade de expansão dos grãos. De cada parcela utilizou-se uma amostra de $30 \mathrm{~mL}$ de grãos, que foram estourados em pipoqueira elétrica, com temperatura controlada, obtendo-se a capacidade de expansão pela razão entre o volume de grãos e o volume de pipoca expandida.

As análises de variância para porcentagens de controle, cobertura vegetal e fitotoxicidade foram realizadas individualmente para cada época de avaliação, sendo os dados transformados em arco-seno $\sqrt{\mathrm{x} / 100}$. Após as análises de variância, procedeu-se às comparações das médias, utilizando-se o teste de agrupamento de Scott-Knott a 5\% de probabilidade.

\section{RESULTADOS E DISCUSSÃO}

De forma geral, a toxicidade dos herbicidas às plantas de milho-pipoca foi baixa (Tabela 1). Verificou-se toxidez moderada à cultura pela aplicação de nicosulfuron e de foramsulfuron + iodosulfuron methyl sodium e que essa toxidez foi mais evidente à medida que se elevaram as doses desses herbicidas e se adicionou espalhante à calda de pulverização (Tabela 1). Todavia, os sintomas de toxidez desapareceram após os 28 DAA, para as doses de $30+2,45+3$ e $60+4$ de foramsulfuron + iodosulfuron methyl sodium, evidenciando a recuperação da cultura.

Planta Daninha, Viçosa-MG, v. 23, n. 3, p. 509-516, 2005 
Tabela 1 - Toxicidade observada no milho-pipoca e cobertura vegetal do solo pelas plantas daninhas aos 7, 14 e 28 dias após a aplicação dos tratamentos (DAA). Coimbra-MG

\begin{tabular}{|c|c|c|c|c|c|c|c|}
\hline \multirow{2}{*}{ Tratamento } & \multirow{2}{*}{$\begin{array}{c}\text { Dose } \\
\left(\mathrm{g} \mathrm{ha}^{-1}\right)\end{array}$} & \multicolumn{3}{|c|}{ Fitotoxicidade (\%) } & \multicolumn{3}{|c|}{ Cobertura vegetal (\%) } \\
\hline & & $7 \mathrm{DAA}$ & $14 \mathrm{DAA}$ & 28 DAA & $7 \mathrm{DAA}$ & 14 DAA & $28 \mathrm{DAA}$ \\
\hline$[\text { atrazine }]^{1 /}$ & 1.500 & $3,3 \mathrm{~b}$ & $0,0 \mathrm{c}$ & $0,0 \mathrm{~b}$ & $14,0 \mathrm{a}$ & $23,3 \mathrm{~b}$ & $63,3 \mathrm{~b}$ \\
\hline [foramsulfuron + iodosulfuron methyl sodium] ${ }^{2 /}+$ atrazine & $15+1+1.500$ & $10,0 \mathrm{~b}$ & $4,3 \mathrm{c}$ & $0,7 \mathrm{~b}$ & $6,7 \mathrm{~b}$ & $1,7 \mathrm{~d}$ & $0,7 \mathrm{c}$ \\
\hline foramsulfuron + iodosulfuron methyl sodium + atrazine & $30+2+1.500$ & $15,0 \mathrm{~b}$ & $3,3 \mathrm{c}$ & $1,7 \mathrm{~b}$ & $3,7 \mathrm{~b}$ & $1,7 \mathrm{~d}$ & $1,0 \mathrm{c}$ \\
\hline foramsulfuron + iodosulfuron methyl sodium* ${ }^{*}$ & $15+1$ & $23,3 \mathrm{a}$ & $3,7 \mathrm{c}$ & $0,0 \mathrm{~b}$ & $2,7 \mathrm{~b}$ & $0,5 \mathrm{~d}$ & $1,3 \mathrm{c}$ \\
\hline foramsulfuron + iodosulfuron methyl sodium* & $30+2$ & $28,3 \mathrm{a}$ & $18,3 \mathrm{~b}$ & $6,7 \mathrm{a}$ & $3,7 \mathrm{~b}$ & $0,7 \mathrm{~d}$ & $1,2 \mathrm{c}$ \\
\hline foramsulfuron + iodosulfuron methyl sodium* & $45+3$ & $33,3 \mathrm{a}$ & $26,7 \mathrm{a}$ & $8,3 \mathrm{a}$ & $2,0 \mathrm{~b}$ & $0,7 \mathrm{~d}$ & $2,2 \mathrm{c}$ \\
\hline foramsulfuron + iodosulfuron methyl sodium* & $60+4$ & $41,7 \mathrm{a}$ & $25,0 \mathrm{a}$ & $10,0 \mathrm{a}$ & $2,5 \mathrm{~b}$ & $0,2 \mathrm{~d}$ & $1,2 \mathrm{c}$ \\
\hline [nicosulfuron] $]^{3 /}$ & 16 & $21,7 \mathrm{a}$ & $6,7 \mathrm{c}$ & $0,0 \mathrm{~b}$ & $7,7 \mathrm{~b}$ & $8,7 \mathrm{c}$ & $13,7 \mathrm{c}$ \\
\hline nicosulfuron + atrazine & $8+1.500$ & $5,0 \mathrm{~b}$ & $0,0 \mathrm{c}$ & $0,0 \mathrm{~b}$ & $4,3 \mathrm{~b}$ & $1,7 \mathrm{~d}$ & $3,7 \mathrm{c}$ \\
\hline nicosulfuron + atrazine & $16+1.500$ & $5,7 \mathrm{~b}$ & $0,0 \mathrm{c}$ & $0,0 \mathrm{~b}$ & $2,2 \mathrm{~b}$ & $1,7 \mathrm{~d}$ & $2,0 \mathrm{c}$ \\
\hline testemunha capinada & --- & $0,0 \mathrm{~b}$ & $0,0 \mathrm{c}$ & $0,0 \mathrm{~b}$ & $0,0 \mathrm{~b}$ & $0,0 \mathrm{~d}$ & $0,0 \mathrm{c}$ \\
\hline testemunha sem capina & --- & $0,0 \mathrm{~b}$ & $0,0 \mathrm{c}$ & $0,0 \mathrm{~b}$ & $21,7 \mathrm{a}$ & $100,0 \mathrm{a}$ & $100,0 \mathrm{a}$ \\
\hline CV (\%) & & 24,7 & 28,7 & 17,2 & 30,1 & 15,7 & 24,2 \\
\hline
\end{tabular}

$\underline{1} / 2 / /$ e $^{\underline{3} /}$ Referem-se aos produtos comerciais Primóleo, Equip Plus e Sanson, respectivamente. * Nestes tratamentos foi aplicado 1 L ha ${ }^{-1}$ do espalhante Hoefix ${ }^{\circledR}$. Médias seguidas pela mesma letra, nas colunas, são estatisticamente iguais pelo teste de Scott-Knott a 5\% de probabilidade.

Resultados de toxidez em milho comum após a aplicação de nicosulfuron são relatados por Moro \& Damião-Filho (1999), que observaram alterações morfológicas e anatômicas nas folhas, com clorose e enrugamento da lâmina foliar, e que tais sintomas desapareceram ao longo do ciclo da cultura. Para o híbrido de milho comum DKB-214, Zagonel (2002) verificou que a aplicação de nicosulfuron e foramsulfuron + iodosulfuron methyl sodium causou leve injúria às plantas, porém com rápida recuperação destas. Em milho-pipoca cultivado em casa de vegetação, Trindade (1995) observou toxicidade do nicosulfuron a partir da dose de $60 \mathrm{~g} \mathrm{ha}^{-1}$ para os cultivares Zélia 01, CMS 43 CII, CMS 42 CI, Rogobras 2, Pirapoca B e Colorado 1, avaliada aos 14 DAA; para a dose inferior a $60 \mathrm{~g} \mathrm{ha}^{-1}$, o nivel de injúria foi semelhante ao da testemunha nãotratada.

Quanto à cobertura vegetal proporcionada pelas plantas daninhas, verificou-se, aos 7 DAA, maior porcentagem de cobertura na testemunha sem capina $(21,7 \%)$ e nas parcelas tratadas com atrazine (14\%), sendo os tratamentos com as sulfoniluréias semelhantes entre si, com cobertura máxima de 7,67\%
(Tabela 1). Até os 28 DAA, as parcelas tratadas com as sulfoniluréias apresentaram cobertura vegetal inferior à da testemunha sem capina (que apresentou $100 \%$ de sua área coberta) e à do tratamento com atrazine (63,3\%). Essa diferença entre a testemunha sem capina e o tratamento com atrazine ocorreu em função do controle de Ipomoea spp. pelo atrazine, enquanto a baixa cobertura vegetal das demais parcelas foi atribuída à ação tóxica das sulfoniluréias sobre as espécies $B$. plantaginea e B. decumbens.

Inicialmente, verificou-se maior sensibilidade de $B$. plantaginea aos herbicidas em relação a $B$. decumbens (Tabela 2 ). As sulfoniluréias, em todas as doses e misturas testadas, proporcionaram controle de $B$. plantaginea acima de $80 \%$ em todas as épocas de avaliação. Comportamento semelhante foi observado para B. decumbens, a partir dos 14 DAA (Tabela 2). Aos 28 DAA, a mistura de foramsulfuron + iodosulfuron methyl sodium, isolado ou associado ao atrazine, proporcionou excelente controle (acima de 90\%) de B. plantaginea e $B$. decumbens, em todas as doses testadas (Tabela 2). Da mesma forma, o nicosulfuron em mistura com atrazine mostrou-se eficiente 
no controle dessas espécies. Entretanto, quando aplicado isoladamente, o controle foi de $80 \%$. O atrazine, por sua vez, não controlou essas espécies daninhas (Tabela 2). Resultados semelhantes quanto à eficiência do controle químico de $B$. plantaginea, utilizandose de sulfoniluréias isoladas ou em mistura com atrazine, são relatados por Bastiani (1997), Merotto Jr. et al. (2000) e Zagonel (2002).

A sensibilidade de espécies de Brachiaria às sulfoniluréias é explicada pela rápida absorção e translocação desses herbicidas para as regiões meristemáticas (Gallaher et al., 1999) e pela elevada atividade da enzima acetolactato sintase (ALS) - enzima-chave na rota de biossíntese dos aminoácidos ramificados e alvo de inibição por esse grupo de herbicidas (Hinz \& Owen, 1996) nessa região da planta (Gerwick et al., 1993).

$\mathrm{Na}$ avaliação realizada em pré-colheita do milho, verificou-se que nenhum dos herbicidas aplicados proporcionou controle de Ipomoea spp. equivalente ao obtido na testemunha capinada. A porcentagem de infestação entre os tratamentos herbicidas variaram de 19 a $52 \%$ com essas espécies, enquanto na testemunha sem capina esse valor atingiu
55\% (Tabela 2). Por possuírem hábito de crescimento trepador e caule resistente, espécies desse gênero podem impedir a colheita mecânica, mesmo sob infestações moderadas. Segundo Deuber \& Duarte (1997), Marcondes et al. (1997) e Bastiani (1997), o atrazine, isoladamente ou em mistura com nicosulfuron, aplicado em pós-emergência geralmente proporciona controle excelente dessas espécies. Todavia, o controle insuficiente proporcionado pelos herbicidas avaliados nesse experimento, provavelmente, ocorreu em virtude da alta freqüência de precipitação pluvial na área experimental após a aplicação dos herbicidas (dados não mostrados), reduzindo-lhes a atividade residual e permitindo a reinfestação da área.

Analisando os teores relativos de clorofila total (indice SPAD) e de macronutrientes no tecido foliar das plantas de milho-pipoca, verificaram-se menores teores de clorofila e de $\mathrm{N}$ nas parcelas tratadas com atrazine e na testemunha sem capina e de P na testemunha sem capina, em comparação aos demais tratamentos (Tabela 3). À exceção da mistura de nicosulfuron + atrazine, foram observados, também, maiores teores de $\mathrm{K}$ na testemunha capinada e nos demais tratamentos com as sulfoniluréias, em relação à testemunha sem

Tabela 2 - Porcentagem de controle de Brachiaria plantaginea e Brachiaria decumbens aos 7, 14 e 28 dias após a aplicação dos tratamentos (DAA) e porcentagem de infestação de Ipomoea spp. em pré-colheita da cultura do milho-pipoca. Coimbra-MG

\begin{tabular}{|c|c|c|c|c|c|c|c|c|}
\hline \multirow{2}{*}{ Tratamento } & \multirow{2}{*}{$\begin{array}{c}\text { Dose } \\
\left(\mathrm{g} \mathrm{ha}^{-1}\right)\end{array}$} & \multicolumn{3}{|c|}{ Brachiaria plantaginea } & \multicolumn{3}{|c|}{ Brachiaria decumbens } & \multirow{2}{*}{$\begin{array}{l}\text { Ipomoea } \\
\text { spp. }\end{array}$} \\
\hline & & 7 DAA & 14 DAA & 28 DAA & $7 \mathrm{DAA}$ & 14 DAA & 28 DAA & \\
\hline${\text { [atrazine }]^{1 /}}^{1 /}$ & 1.500 & $10,0 \mathrm{~d}$ & $0,0 \mathrm{c}$ & $0,0 \mathrm{c}$ & $3,3 \mathrm{~b}$ & $0,0 \mathrm{~b}$ & $0,0 \mathrm{c}$ & $19,7 \mathrm{c}$ \\
\hline [foramsulfuron + iodosulfuron methyl sodium $]^{2}+$ atrazine & $15+1+1.500$ & $91,7 \mathrm{a}$ & $99,3 \mathrm{a}$ & $99,3 \mathrm{a}$ & $80,0 \mathrm{a}$ & $94,3 \mathrm{a}$ & $90,0 \mathrm{a}$ & $22,7 \mathrm{c}$ \\
\hline foramsulfuron + iodosulfuron methyl sodium + atrazine & $30+2+1.500$ & $93,3 \mathrm{a}$ & $98,7 \mathrm{a}$ & $99,3 \mathrm{a}$ & $78,3 \mathrm{a}$ & $89,0 \mathrm{a}$ & $91,7 \mathrm{a}$ & $24,7 \mathrm{c}$ \\
\hline foramsulfuron + iodosulfuron methyl sodium* & $15+1$ & $81,7 \mathrm{c}$ & $98,3 \mathrm{a}$ & $97,0 \mathrm{a}$ & $75,0 \mathrm{a}$ & $93,3 \mathrm{a}$ & $91,7 \mathrm{a}$ & 46,4 a \\
\hline foramsulfuron + iodosulfuron methyl sodium* & $30+2$ & $88,3 \mathrm{~b}$ & $98,0 \mathrm{a}$ & $97,7 \mathrm{a}$ & $78,3 \mathrm{a}$ & $94,0 \mathrm{a}$ & $95,0 \mathrm{a}$ & $50,3 \mathrm{a}$ \\
\hline foramsulfuron + iodosulfuron methyl sodium* & $45+3$ & $94,0 \mathrm{a}$ & $98,7 \mathrm{a}$ & $100,0 \mathrm{a}$ & $85,0 \mathrm{a}$ & $91,7 \mathrm{a}$ & $99,3 \mathrm{a}$ & $52,3 \mathrm{a}$ \\
\hline foramsulfuron + iodosulfuron methyl sodium* & $60+4$ & $94,0 \mathrm{a}$ & $99,7 \mathrm{a}$ & $96,7 \mathrm{a}$ & $86,7 \mathrm{a}$ & $95,0 \mathrm{a}$ & $93,3 \mathrm{a}$ & $46,4 \mathrm{a}$ \\
\hline [nicosulfuron] $]^{3}-m-m-m$ & 16 & $94,3 \mathrm{a}$ & $94,3 \mathrm{~b}$ & $81,7 \mathrm{~b}$ & $55,0 \mathrm{a}$ & $87,7 \mathrm{a}$ & $78,3 \mathrm{~b}$ & $37,5 \mathrm{~b}$ \\
\hline nicosulfuron + atrazine & $8+1.500$ & $82,5 \mathrm{c}$ & $98,7 \mathrm{a}$ & $100,0 \mathrm{a}$ & $70,0 \mathrm{a}$ & 93,3 a & $100,0 \mathrm{a}$ & $39,5 \mathrm{~b}$ \\
\hline nicosulfuron + atrazine & $16+1.500$ & $94,0 \mathrm{a}$ & $99,0 \mathrm{a}$ & $100,0 \mathrm{a}$ & $81,7 \mathrm{a}$ & $94,7 \mathrm{a}$ & $97,7 \mathrm{a}$ & $39,5 b$ \\
\hline testemunha capinada & --- & $100,0 \mathrm{a}$ & $100,0 \mathrm{a}$ & $100,0 \mathrm{a}$ & $100,0 \mathrm{a}$ & $100,0 \mathrm{a}$ & $100,0 \mathrm{a}$ & $0 \mathrm{~d}$ \\
\hline testemunha sem capina & --- & $0,0 \mathrm{e}$ & $0,0 \mathrm{c}$ & $0,0 \mathrm{c}$ & $0,0 \mathrm{~b}$ & $0,0 \mathrm{~b}$ & $0,0 \mathrm{c}$ & $55,3 \mathrm{a}$ \\
\hline CV (\%) & & 4,5 & 1,7 & 7,0 & 21,5 & 7,1 & 7,9 & 19,0 \\
\hline
\end{tabular}

${ }^{1 /},{ }^{2 /} \mathrm{e}^{\underline{3} / /}$ Referem-se aos produtos comerciais Primóleo, Equip Plus e Sanson, respectivamente. * Nestes tratamentos foi aplicado 1 L ha ${ }^{-1}$ do espalhante Hoefix ${ }^{\circledR}$. Médias seguidas pela mesma letra, nas colunas, são estatisticamente iguais pelo teste de Scott-Knott a 5\% de probabilidade. 
capina e ao atrazine isolado (Tabela 3). Os teores de $\mathrm{Ca}, \mathrm{Mg}$ e $\mathrm{S}$ não foram influenciados pelos tratamentos e permaneceram na faixa considerada adequada para a cultura, de acordo com dados obtidos para o milho comum (Malavolta et al., 1989) (Tabela 3).

Os teores de $\mathrm{N}$ das parcelas que se encontravam sob infestação de plantas daninhas ficaram abaixo do limite inferior da faixa considerada adequada por Malavolta et al. (1989) para cultivares de milho comum. Segundo Rocha (2003), o teor relativo de clorofila na folha, avaliado no florescimento do milho, se correlaciona positivamente com o teor de $\mathrm{N}$ na planta, que por sua vez se correlaciona com o rendimento de grãos. Essa associação referese ao fato de que a maior parte do $\mathrm{N}$ encontrado nas folhas constitui as enzimas que estão associadas aos cloroplastos e à capacidade fotossintética da planta. Menores teores de

Tabela 3 - Índice SPAD e teores foliares de N, P, K, Ca, Mg e S avaliados no florescimento da cultura de milho-pipoca. Coimbra-MG

\begin{tabular}{|c|c|c|c|c|c|c|c|c|}
\hline \multirow{2}{*}{ Tratamento } & \multirow{2}{*}{$\begin{array}{c}\text { Dose } \\
\left(\mathrm{g} \mathrm{h} \mathrm{h}^{-1}\right)\end{array}$} & \multirow{2}{*}{$\begin{array}{l}\text { Índice } \\
\text { SPAD }\end{array}$} & $\mathrm{N}$ & $\mathrm{P}$ & $\mathrm{K}$ & $\mathrm{Ca}$ & $\mathrm{Mg}$ & $\mathrm{S}$ \\
\hline & & & \multicolumn{6}{|c|}{$\left(\right.$ dag kg $\left.^{-1}\right)$} \\
\hline${\text { [atrazine }]^{1 /}}^{1 /}$ & 1.500 & $48,23 \mathrm{~b}$ & $2,69 \mathrm{~b}$ & $0,35 \mathrm{a}$ & $1,75 \mathrm{~b}$ & $0,39 \mathrm{a}$ & $0,38 \mathrm{a}$ & $0,15 \mathrm{a}$ \\
\hline [foramsulfuron + iodosulfuron methyl sodium] $]^{21}+$ atrazine & $15+1+1.500$ & $54,30 \mathrm{a}$ & $3,15 \mathrm{a}$ & $0,37 \mathrm{a}$ & $2,10 \mathrm{a}$ & $0,39 \mathrm{a}$ & $0,37 \mathrm{a}$ & $0,17 \mathrm{a}$ \\
\hline foramsulfuron + iodosulfuron methyl sodium + atrazine & $30+2+1.500$ & $54,63 \mathrm{a}$ & $2,99 \mathrm{a}$ & $0,34 \mathrm{a}$ & $1,90 \mathrm{a}$ & $0,40 \mathrm{a}$ & $0,40 \mathrm{a}$ & $0,15 \mathrm{a}$ \\
\hline foramsulfuron + iodosulfuron methyl sodium* & $15+1$ & $56,60 \mathrm{a}$ & 2,86 a & $0,37 \mathrm{a}$ & $2,02 \mathrm{a}$ & $0,43 \mathrm{a}$ & $0,37 \mathrm{a}$ & $0,18 \mathrm{a}$ \\
\hline foramsulfuron + iodosulfuron methyl sodium* & $30+2$ & $53,37 \mathrm{a}$ & $2,98 \mathrm{a}$ & $0,32 \mathrm{a}$ & $2,04 \mathrm{a}$ & $0,40 \mathrm{a}$ & $0,35 \mathrm{a}$ & $0,16 \mathrm{a}$ \\
\hline foramsulfuron + iodosulfuron methyl sodium* & $45+3$ & $52,47 \mathrm{a}$ & $3,05 \mathrm{a}$ & $0,34 \mathrm{a}$ & $2,02 \mathrm{a}$ & $0,35 \mathrm{a}$ & $0,35 \mathrm{a}$ & $0,17 \mathrm{a}$ \\
\hline foramsulfuron + iodosulfuron methyl sodium* & $60+4$ & $54,70 \mathrm{a}$ & 3,08 a & $0,35 \mathrm{a}$ & $1,90 \mathrm{a}$ & $0,34 \mathrm{a}$ & $0,35 \mathrm{a}$ & $0,16 \mathrm{a}$ \\
\hline [nicosulfuron] $]^{3 /}$ & 16 & $52,47 \mathrm{a}$ & $2,93 \mathrm{a}$ & $0,33 \mathrm{a}$ & $1,90 \mathrm{a}$ & $0,35 \mathrm{a}$ & $0,37 \mathrm{a}$ & $0,18 \mathrm{a}$ \\
\hline nicosulfuron + atrazine & $8+1.500$ & $55,37 \mathrm{a}$ & $2,98 \mathrm{a}$ & $0,35 \mathrm{a}$ & $1,80 \mathrm{~b}$ & $0,37 \mathrm{a}$ & $0,33 \mathrm{a}$ & $0,17 \mathrm{a}$ \\
\hline nicosulfuron + atrazine & $16+1.500$ & $54,03 \mathrm{a}$ & 2,98 a & $0,33 \mathrm{a}$ & $1,81 \mathrm{~b}$ & $0,39 \mathrm{a}$ & $0,37 \mathrm{a}$ & $0,18 \mathrm{a}$ \\
\hline testemunha capinada & --- & $51,40 \mathrm{a}$ & $3,12 \mathrm{a}$ & $0,40 \mathrm{a}$ & $2,23 \mathrm{a}$ & $0,43 \mathrm{a}$ & $0,36 \mathrm{a}$ & $0,18 \mathrm{a}$ \\
\hline testemunha sem capina & --- & $45,03 \mathrm{~b}$ & $2,45 \mathrm{c}$ & $0,28 \mathrm{~b}$ & $1,65 \mathrm{~b}$ & $0,35 \mathrm{a}$ & $0,31 \mathrm{a}$ & $0,19 \mathrm{a}$ \\
\hline CV (\%) & & 3,78 & 4,74 & 9,06 & 8,98 & 15,78 & 11,14 & 7,14 \\
\hline
\end{tabular}

${ }^{1 /}, \underline{2} / \mathrm{e}^{\underline{3} /}$ Referem-se aos produtos comerciais Primóleo, Equip Plus e Sanson, respectivamente. * Nestes tratamentos foi aplicado 1 L ha ${ }^{-1}$ do espalhante Hoefix®. Médias seguidas pela mesma letra, nas colunas, são estatisticamente iguais pelo teste de Scott-Knott a $5 \%$ de probabilidade.

Tabela 4 - Rendimento e capacidade de expansão (CE) de grãos de milho-pipoca nos tratamentos aplicados. Coimbra-MG

\begin{tabular}{|c|c|c|c|}
\hline Tratamento & $\begin{array}{l}\text { Dose } \\
\left(\mathrm{g} \mathrm{ha}^{-1}\right)\end{array}$ & $\begin{array}{l}\text { Rendimento } \\
\left(\mathrm{kg} \mathrm{ha}^{-1}\right)\end{array}$ & $\begin{array}{c}\mathrm{CE} \\
\left(\mathrm{v} \mathrm{v}^{-1}\right)\end{array}$ \\
\hline [atrazine] $^{1 /}$ & 1.500 & $2.616 \mathrm{~b}$ & $22,70 \mathrm{a}$ \\
\hline 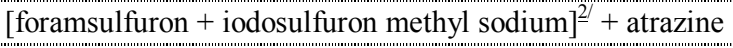 & $15+1+1.500$ & $3.267 \mathrm{a}$ & $21,26 \mathrm{a}$ \\
\hline foramsulfuron + iodosulfuron methyl sodium + atrazine & $30+2+1.500$ & $3.412 \mathrm{a}$ & $24,60 \mathrm{a}$ \\
\hline foramsulfuron + iodosulfuron methyl sodium* & $15+1$ & $3.273 \mathrm{a}$ & $21,50 \mathrm{a}$ \\
\hline foramsulfuron + iodosulfuron methyl sodium* & $30+2$ & $3.356 \mathrm{a}$ & $22,26 \mathrm{a}$ \\
\hline foramsulfuron + iodosulfuron methyl sodium* & $45+3$ & $3.168 \mathrm{a}$ & $20,66 \mathrm{a}$ \\
\hline foramsulfuron + iodosulfuron methyl sodiumen* & $60+4$ & $\begin{array}{ll}3.103 \mathrm{a} \\
3.103\end{array}$ & $21,33 \mathrm{a}$ \\
\hline 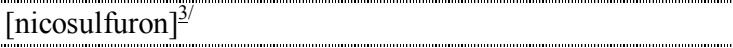 & 16 & $3.489 \mathrm{a}$ & $19,93 \mathrm{a}$ \\
\hline nicosulfuron + atrazine & $8+1.500$ & $3.362 \mathrm{a}$ & $19,33 \mathrm{a}$ \\
\hline nicosulfuron + atrazine & $16+1.500$ & $3.338 \mathrm{a}$ & $21,27 \mathrm{a}$ \\
\hline testemunha capinada & --- & $3.499 \mathrm{a}$ & $20,73 \mathrm{a}$ \\
\hline testemunha sem capina & --- & $2.067 \mathrm{~b}$ & $20,97 \mathrm{a}$ \\
\hline CV $(\%)$ & & 12,94 & 10,09 \\
\hline
\end{tabular}

${ }^{1 /},{ }^{2 /} \mathrm{e}^{3 /}$ Referem-se aos produtos comerciais Primóleo, Equip Plus e Sanson, respectivamente. * Nestes tratamentos foi aplicado $1 \mathrm{~L} \mathrm{ha}^{-1}$ do espalhante Hoefix ${ }^{\circledR}$. Médias seguidas pela mesma letra, nas colunas, são estatisticamente iguais pelo teste de Scott-Knott a 5\% de probabilidade. 
clorofila total e de $\mathrm{N}$ foliar e, conseqüentemente, menor rendimento de grãos foram obtidos por Souza (1996) e Zagonel et al. (2000) em milho comum sob interferência de plantas daninhas.

A competição das plantas daninhas com a cultura causou redução no rendimento de grãos de ordem de 38\% na testemunha sem capina e de $22 \%$ no tratamento com atrazine isoladamente, comparativamente às médias dos tratamentos com as sulfoniluréias e a testemunha capinada, entre as quais não houve diferenças significativas (Tabela 4). De acordo com Kawazaki (2001), a característica que melhor avalia a qualidade da pipoca é a capacidade de expansão dos grãos quando estourados. Dessa forma, observou-se que a presença das plantas daninhas, bem como os tratamentos empregados no seu controle, não afetou a capacidade de expansão dos grãos (Tabela 4).

Diante do exposto, pode-se concluir, para esse cultivar de milho-pipoca, que a mistura pronta foramsulfuron + iodosulfuron methyl sodium, associados ou não ao atrazine, e o nicosulfuron em mistura com atrazine, nas doses testadas, foram eficientes no controle de $B$. plantaginea e de $B$. decumbens, sem comprometer o estado nutricional, o rendimento e a capacidade de expansão dos grãos de milhopipoca.

\section{LITERATURA CITADA}

BASTIANI, M. L. R. Atividade dos herbicidas nicosulfuron e atrazine, em condições de casa de vegetação e de campo. 1997. 59 f. Dissertação (Mestrado em Fitotecnia) Universidade Federal de Viçosa, Viçosa, 1997.

BRAGA, J. M.; DEFFELIPO, B. V. Determinação espectrofotométrica de fósforo em extratos de solo e plantas. R. Ceres, v. 21, p. 73-85, 1974.

DEUBER, R.; DUARTE, A. P. Manejo da flora infestante em milho "safrinha" com misturas de subdoses de atrazine + óleo vegetal com 2,4-D. In: CONGRESSO BRASILEIRO DA CIÊNCIA DAS PLANTAS DANINHAS, 21., 1997. Caxambu, MG. Resumos... Caxambu, MG: SBCPD, 1997. p. 211.

GALLAHER, K. et al. Absorption, translocation and metabolism of primisulfuron and nicosulfuron in broadleaf signalgrass (Brachiaria platyphylla) and corn. Weed Sci., v. 47, p. $8-12,1999$.
GERWICK, B. C.; MIRELES. L. C.; EILERS, R. J. Rapid diagnosis of ALS/AHAS resistant weeds. Weed Technol., v. 7, p. 519-524, 1993.

GUBBIGA, N. G.; WORSHAM, A. D.; COBLE, H. D. Effect of nicosulfuron on johnsongrass (Sorghum halepense) control and corn (Zea mays) performance. Weed Technol., v. 9, p. 3574-3581, 1995.

HINZ, J. R.; OWEN, M. K. Nicosulfuron and primisulfuron selectivity in corn and two grass weeds. Weed Sci., v. 44, p. 219-223, 1996

JACKSON, M. L. Nitrogen determination for soil and plant tissue. In: JACKSON, M. L. (Ed.) Soil chemical analysis. Englewood Cliffs: Prentice-Hall, 1958. p. 183-204.

KAWAZAKI, E. A cultura do milho pipoca no Brasil. o agronômico, v. 53, n. 2, 2001. Disponível em: <http:// www.iac.sp.gov.br/new/oagronomico532/11_pipoca.pdf>. Acesso em: 2 abr. 2004.

MALAVOLTA, E.; VITTI, G. C.; OLIVEIRA, S. A. Avaliação do estado nutricional das plantas: princípios e aplicações. Piracicaba: POTAFOS, 1989. 201 p.

MARCONDES, D. D.; CHEHATA, A. N.; FORNAROLII, D. A. Efeitos da adição de óleo vegetal ou espalhante a calda do atrazine na cultura do milho. In: CONGRESSO BRASILEIRO DA CIÊNCIA DAS PLANTAS DANINHAS, 21., 1997. Caxambu, MG. Resumos... Caxambu: SBCPD, 1997. p. 217.

MEROTTO JR., A. et al. Redução da interferência de Brachiaria plantaginea (Link) Hitch. em milho através de capinas e aplicação de herbicidas em diferentes épocas. Planta Daninha, v. 18, n. 3, p. 474-477, 2000.

MEROTTO JR., A. et al. Aumento da população de plantas e uso de herbicidas no controle de plantas daninhas em milho. Planta Daninha, v. 15, n. 2, p. 141-151, 1997.

MORO, F. V.; DAMIÃO-FILHO, C. F. Alterações morfoanatômicas das folhas de milho submetidas à aplicação de nicosulfuron. Planta Daninha, v. 17, n. 3, p. 331-337, 1999.

ROCHA, R. C. N. Respostas de híbridos de milho e ciclo superprecoce, precoce e normal à aplicação de nitrogênio no sistema de plantio direto. 2003. $47 \mathrm{f}$. Dissertação (Mestrado em Fitotecnia) - Universidade Federal de Viçosa, Viçosa, 2003.

RODRIGUES, B. N.; ALMEIDA, F. S. Guia de herbicidas. 4.ed. Londrina: Edição dos autores, 1998. 648 p.

SILVA, A. A.; FERREIRA, F. A.; FERREIRA, L. R. Biologia e controle de plantas daninhas. Viçosa: DFT/ UFV, 2002. CD-ROM.

Planta Daninha, Viçosa-MG, v. 23, n. 3, p. 509-516, 2005 
SOUZA, J. R. P. Período de controle de plantas daninhas, crescimento e produtividade da cultura do milho (Zea mays L.). 1996. 91 f. Tese (Doutorado em Fitotecnia) - UNESP, Botucatu, 1996.

SULLIVAN, J. O.; BOUW, W. J. Sensitivity of processing sweet corn (Zea mays) cultivars to nicosulfuron/rimsulfuron. Canadian J. Plant Sci., v. 41, n. 1, p. 151-154, 1997.

TRINDADE, F. A. Estudo da tolerância de cultivares de milho pipoca (Zea mays L.) a herbicidas. 1995. $105 \mathrm{f}$. Dissertação (Mestrado em Fitotecnia) - Universidade Federal de Lavras, Lavras, 1995.
ZAGONEL, J. Eficácia do Equip Plus no controle de plantas daninhas na cultura do milho em plantio direto. Boletim Informativo SBCPD, v. 8, n. 2, p. 27-32, 2002.

ZAGONEL, J.; VENANCIO, W. S.; KUNS, R. P. Efeitos de épocas e métodos de controle de plantas daninhas na cultura do milho. Planta Daninha, v. 18, n. 1, p. 143-150, 2000 .

ZIEGLER, K. E.; ASHMAN, B. Popcorn. In: HALLAUER, A. R. (Ed.) Specialty corns. Ames: CRC Press, 1994. p. 189-223. 